\title{
Increasing incidence of cancer and stage migration towards advanced disease in children and young adolescents in the Netherlands, 1990-2017
}

\author{
Ardine M.J. Reedijk ${ }^{a, 1}$, Leontien C. Kremer ${ }^{a, b, 1}$, Otto Visser ${ }^{c}$, \\ Valery Lemmens ${ }^{\mathrm{c}, \mathrm{d}}$, Rob Pieters ${ }^{\mathrm{a}}$, Jan Willem W. Coebergh ${ }^{\mathrm{d}}$, \\ Henrike E. Karim-Kos ${ }^{\text {a,c,* }}$
}

\footnotetext{
a Princess Máxima Center for Pediatric Oncology, Utrecht, The Netherlands

${ }^{\mathrm{b}}$ Department of Pediatrics, Amsterdam UMC, Amsterdam, The Netherlands

${ }^{\mathrm{c}}$ Department of Research and Development, Netherlands Comprehensive Cancer Organisation (IKNL), Utrecht, The

Netherlands

${ }^{\mathrm{d}}$ Department of Public Health, Erasmus MC University Medical Center Rotterdam, Rotterdam, The Netherlands
}

Received 5 February 2020; received in revised form 31 March 2020; accepted 3 April 2020

Available online 7 June 2020

\section{KEYWORDS \\ Adolescent; \\ Cancer; \\ Childhood; \\ Incidence; \\ Netherlands; \\ Stage at diagnosis}

\begin{abstract}
Background: This is the first national study on trends in cancer incidence for children and young adolescents in the Netherlands, including stage at diagnosis as a potential marker of early diagnosis and better staging.

Methods: All neoplasms in patients younger than 18 years, diagnosed between 1990 and 2017 $(N=15,233)$, were derived from the Netherlands Cancer Registry. Incidence rates and the average annual percentage change with $95 \%$ CIs were calculated for all cancers combined and diagnostic (sub)groups. The stability of trends was examined by joinpoint analyses. Potential changes in early detection or improved staging over time were evaluated through proportional alterations in stage at diagnosis.

Results: The annual overall cancer incidence increased significantly over time by $0.6 \%$ (95\% CI 0.3-0.8) from 144 per million person-years in 1990-1999 to 162 in 2010-2017 and was significant for both boys $(+0.5 \%, 0.2-0.8)$ and girls $(+0.7 \%, 0.3-1.1)$, for infants (aged 0 years; $+1.5 \%, 0.4-2.5$ ), teenagers (aged $10-14$ years; $+0.6 \%, 0.3-1.0$ ) and young adolescents (aged $15-17$ years; $+0.7 \%, 0.2-1.2)$, with no trend interruptions. The incidence of leukaemia $(+0.7 \%, 0.3-1.2)$, malignant CNS tumours including pilocytic astrocytomas $(+1.0 \%, 0.5$ $-1.5)$, neuroblastoma $(+1.2 \%, 0.1-2.2)$ and Ewing bone tumours $(+2.4 \%, 0.9-4.0)$ increased significantly, whereas temporal variation in trends was observed in boys diagnosed with
\end{abstract}

\footnotetext{
* Corresponding author: Princess Máxima Center for Pediatric Oncology, PO Box 113, 3720 AC Bilthoven, The Netherlands.

E-mail address: h.e.karim-kos@prinsesmaximacentrum.nl (H.E. Karim-Kos).

${ }^{1}$ These authors contributed equally to this work.
} 
leukaemia, in pilocytic astrocytoma and malignant melanoma. The proportion of early-stage disease increased in patients with testicular germ cell tumours $(+21 \%)$ and malignant melanomas $(+14 \%)$, whereas stage migration towards advanced disease was seen for Hodgkin lymphomas, soft tissue sarcomas and medullary thyroid carcinomas.

Conclusion: The increasing childhood cancer incidence could not be explained by a rise in early diagnosis, which suggests that background risk factors seem of more importance.

(c) 2020 Elsevier Ltd. All rights reserved.

\section{Introduction}

The incidence of childhood cancer is increasing over time in Europe [1]. Fortunately, survival of childhood cancer improved from about $40 \%$ in the 1960 s to nearly $80 \%$ nowadays $[2,3]$. However, cancer is still one of the leading causes of death in children and adolescents [4].

In a recent analysis of data from 19 European countries, incidence trends of three common diagnostic groups of childhood cancer were studied [1]. Increasing incidence was observed for leukaemia in both children and adolescents $(+0.7 \%$ and $+0.9 \%$ per year, respectively), lymphoma in adolescents $(+1.0 \%$ per year) and malignant tumours of the central nervous system (CNS) in children $(+0.5 \%$ per year). Those increases are generally attributed to improved diagnostics and registration practices, and/or changes in the prevalence of risk factors $[1,5]$. New and improved methods for cancer diagnosis are often more precise and may result in earlier diagnosis and even more diagnosis of indolent cancers or cancers with a bad prognosis previously not diagnosed during a patient's lifetime. More precise diagnostics may also lead to an increase in the occurrence of advanced-stage disease resulting in the so-called stage-migration. Therefore, information on stage at diagnosis could be useful to understand trends in incidence.

In the Netherlands, since 2002, young adolescents until the age of 18 years are usually treated in paediatric oncology centres as in many other European countries [6]. Until now, no comprehensive national trend analyses on incidence of childhood cancer for the Netherlands have been performed. The incidence of childhood cancer has been only described for the ages 0-14 years in the South of the Netherlands until 1999. In this study, an increasing incidence trend $(+3 \%$ per year) was observed until 1997 and this flattened out afterwards [7]. Therefore, an up-to-date populationbased estimation of the incidence of childhood cancer, including young adolescents, is needed.

In this present study, we evaluate incidence trends of cancer in children and young adolescents aged below 18 years and potential changes in early detection and staging through proportional alteration in disease stage at diagnosis in the Netherlands between 1990 and 2017 using population-based data of the Netherlands Cancer Registry (NCR).

\section{Patients and methods}

\subsection{Data collection}

Data on all malignant neoplasms in patients younger than 18 years, diagnosed between 1990 and 2017, were derived from the NCR, a nationwide population-based cancer registry since 1989 . The NCR is based on notification of all newly diagnosed malignancies in the Netherlands by the automated national pathological archive PALGA with additional reporting by hospital discharge registries and the haematology departments. After notification, trained registration personnel collect relevant information from medical records at the hospitals. Since 2000, benign and borderline tumours of the CNS (ICD-O-3, behaviour codes/0 and/1) are included in the NCR. Those tumours were taken into account in Figs. 1 and 2 only, to give a comprehensive overview of all childhood cancers. Pilocytic astrocytomas (ICD-O-3 M9421/1) were completely registered for the period 1990-2017 and therefore included in all analyses. Several other neoplasms were excluded because of incomplete registration during the study period: myelodysplastic syndromes (ICD-O-3 M codes starting with 998, registered since 2001, $N=94$ ), myeloproliferative neoplasms (ICD-O-3 M9950-9962, registered since 2001, $N=26$ ), Langerhans cell histiocytosis (ICD-O-3 M97509754, not consistently registered before $2012, N=152$ ), carcinoid tumour of the appendix (ICD-O-3 site code C18.1, M8240-M8249, before 2013 not consistently registered as $/ 3, N=221$ ). Well-differentiated chondrosarcomas (ICD-O-3 M9220/31, $N=28$ ) and dermatofibrosarcomas (ICD-O-3 M8832, $N=74$ ) were also excluded as they are classified as borderline neoplasms in the newest ICD-O classification (ICD-O-3.2).

Neoplasms were categorised according to the International Classification of Childhood Cancer (ICCC, third edition) [8]. The stage was classified using the Ann Arbor staging system for lymphomas [9], TNM classification or the extent of disease (i.e. localised, regional and distant) for other solid tumours [10]. Early-stage disease at diagnosis was defined as Ann Arbor stage I for lymphomas, and as localised disease for other solid tumours defined by the Toronto Paediatric Cancer Staging guidelines [11]. Early-stage disease of malignant melanomas and thyroid carcinomas are not defined by the 


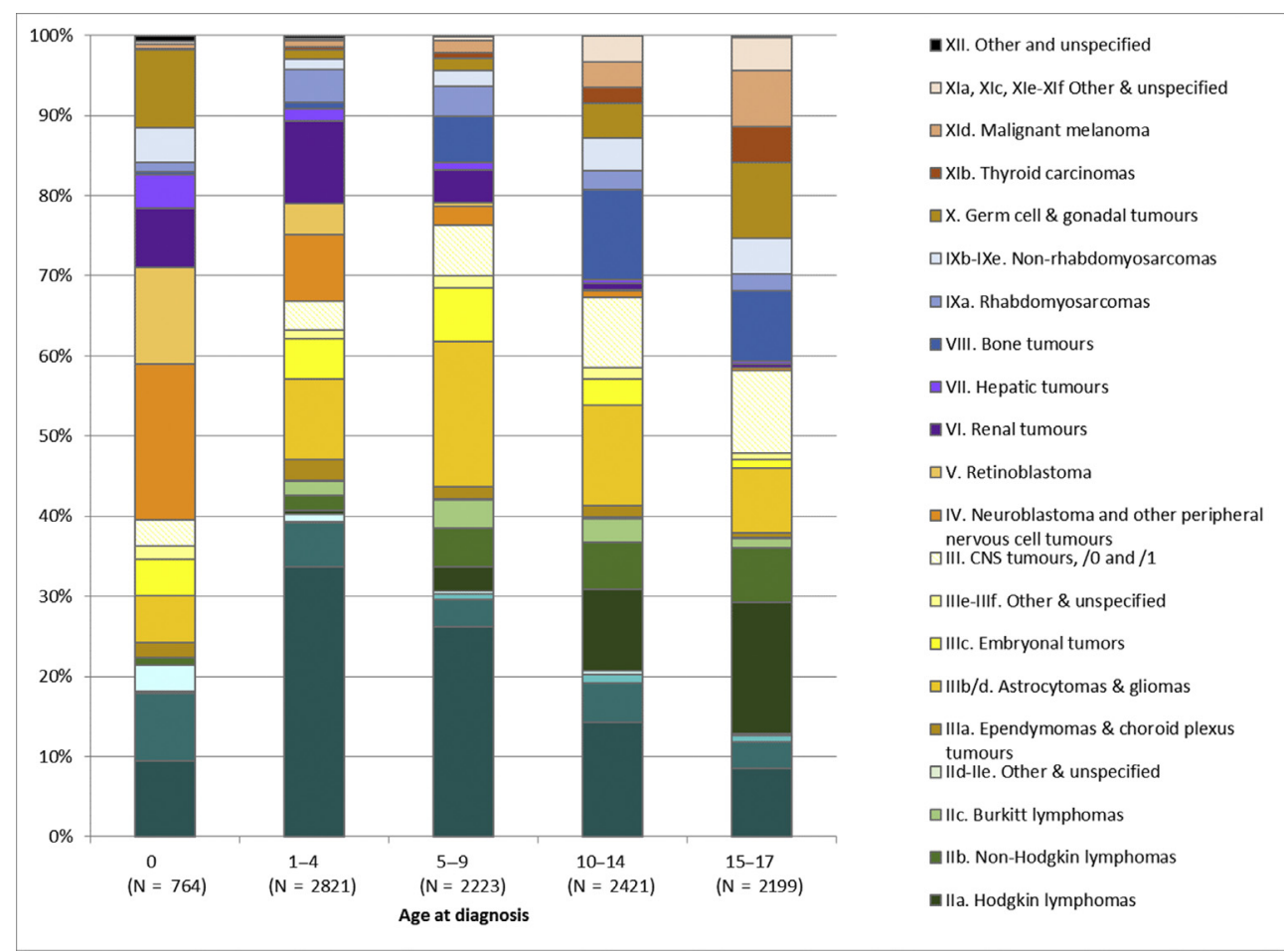

Fig. 1. Relative frequencies (in \%) of diagnostic (sub)groups according to the International Classification of Childhood Cancer (ICCC)-3 classification [including benign and borderline central nervous system (CNS) tumours] by age group in children and young adolescents in the Netherlands, 2000-2017 (Source: The Netherlands Cancer Registry).

Toronto guidelines and therefore based on TNM classification: M0/X for papillary/follicular, T1-4 N0/X M0/X for medullary thyroid carcinomas and T1-2 N0/X M0/X for malignant melanomas (Table S1). For astrocytomas (i.e. ICCC-3 diagnostic subgroup IIIb), the degree of malignancy, WHO grade was used [36]. WHO grade was derived from the sixth digit of the ICD-O morphology code and cross-checked with the first four digits of the morphology code. In case of discrepancies, registry files were checked by one of the authors (OV). Low degree of malignancy was defined as WHO grade I/II.

\subsection{Statistical analyses}

Descriptive analysis of the average number per year and proportions of diagnosis by ICCC-3 diagnostic groups and main subgroups was performed. Incidence was calculated as the average annual number of cases per million person-years. Age-standardised incidence rates (ASR) were calculated for the age group 0-17 years using the weights of the world standard population [12], and age-specific incidence rates were given to the age groups: $0,1-4,5-9,10-14$ and $15-17$ years. Incidence rates were presented in the figures as three-year moving averages by taking the average of the rates of each given year and the rates either side of it. The study period was divided into three periods: 1990-1999, 2000-2009 and 2010-2017.

Changes in incidence over time were evaluated by calculating the average annual percentage change
(AAPC) and corresponding 95\% confidence interval (CI) calculated for the period 1990-2017. AAPC was estimated from a regression line that was fitted to the natural logarithm of the rates using the calendar year as a regressor variable and calculated for the period 1990-2017 [13]. The null hypothesis corresponds to no change in the annual rate during the study period, which was equivalent to 0 lying within the $95 \% \mathrm{CI}$ of the AAPC. Benign and borderline CNS tumours were not taken into account in those trend analyses, and trends were separately described for the period 2000-2017 in Table S2. Joinpoint regression program (version 4.5.0.1) was used to check for trend transitions during the study period $[14,15]$. The null hypothesis assumed that the AAPC was constant throughout the study period. The permutation test [15] was used to determine the number of joinpoints, by default set to a maximum of four. For each detected joinpoint, the AAPC and corresponding 95\% CIs were reported for each of the linear segments identified prior and next to the detected joinpoint. AAPC and joinpoint analyses were performed for all cancers combined and by gender, age, diagnostic groups and main subgroups.

To determine changes in disease stage at diagnosis, proportional alterations in all stages and early stage versus advanced stage over time were evaluated and tested by $\chi^{2}$ test for each diagnostic group, except for group I. Leukaemias and group XII. Other and unspecified tumours. Unknown stages were excluded for this analysis $(N=767,8 \%$ of the total included cancer diagnosis, Table $\mathrm{S} 1)$. 

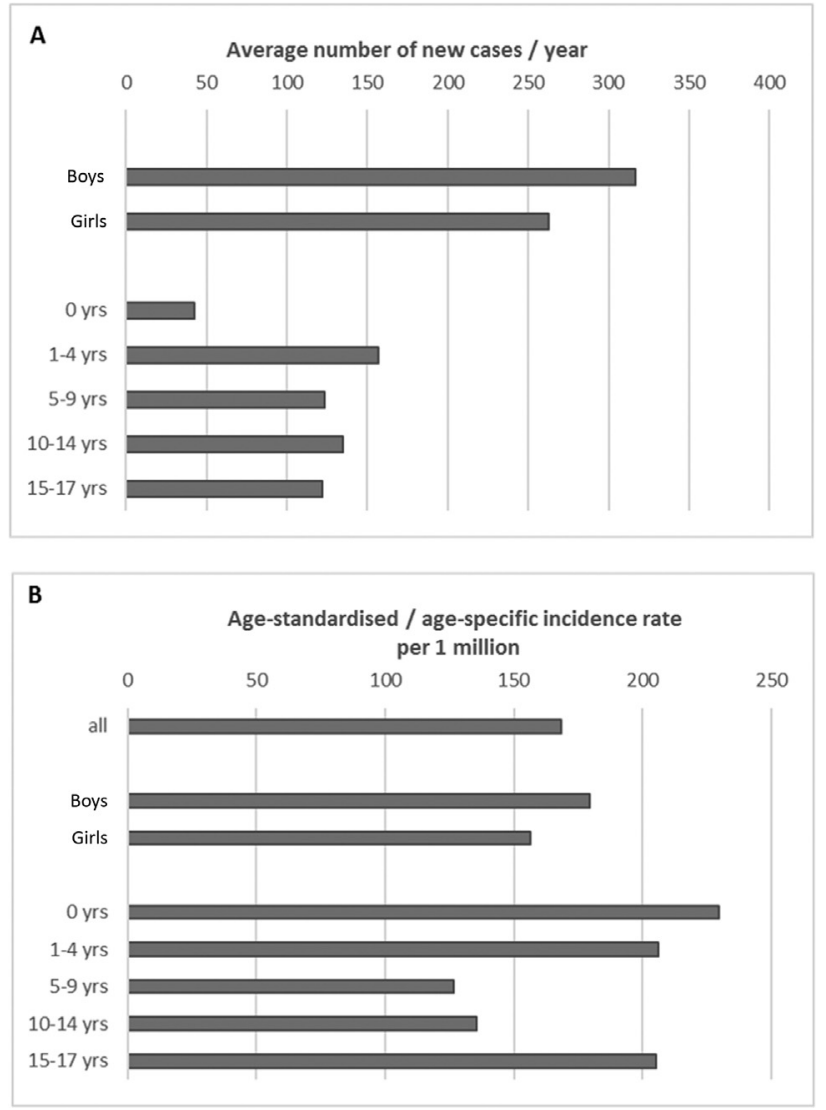

Fig. 2. Incidence of childhood and adolescent cancer by gender and age (including benign and borderline CNS tumours) in the Netherlands, 2000-2017 (Source: The Netherlands Cancer Registry). A) Average number of new cases per year by gender and age. In total, on average, 579 children and young adolescents were diagnosed with cancer in the Netherlands annually. B) Incidence rates by gender and age. Age-standardised rates were calculated for all, boys and girls [12], and age-specific rates for the given age groups.

All analyses were performed using SAS software (SAS system 9.4, SAS Institute, Cary, NC, USA).

\section{Results}

In total, 15,233 cancer diagnoses in children and young adolescents were registered during 1990-2017, including 706 diagnoses of benign and borderline CNS tumours, which were included in the NCR since 2000. For the period 2000-2017, those CNS tumours comprised $7 \%$ of all new cancer diagnoses, and almost $30 \%$ of all new CNS cancer diagnoses. The proportion of benign and borderline CNS tumours varied by age from $5 \%$ of all new cancer diagnoses and $18 \%$ of all new CNS cancer diagnoses in children aged below 10 years to $10 \%$ and $50 \%$ in young adolescents aged $15-17$ years.

Fig. 1 describes the distribution of the different diagnostic childhood cancer groups during 2000-2017. About one-third (34\%) was diagnosed before the age of 5 years and $21 \%$ in the age range $15-17$ years. The most common cancer types among infants (0 years) were leukaemia and neuroblastomas, including other peripheral nervous cell tumours, comprising $40 \%$ of all new cancer diagnoses in infants. Leukaemia was the most common type of cancer in children of $1-9$ years $(31 \%$ of all new cancer diagnoses in this age group). Lymphoma became more common from the age of 10 years: $21 \%$ of all new cancer diagnosis in 10-17 years old compared to $<5 \%$ in children below 5 years. In the younger age, Burkitt lymphoma was common, whereas Hodgkin lymphoma was more present at the older ages. Bone tumours were also common in 10-17 years old patients, resulting in about $10 \%$ of all new cancer diagnoses in this age group. Epithelial cancers became an important group in the age group of $15-17$ years, comprising $16 \%$ of all new cancer diagnoses in those young adolescents.

\subsection{Cancer incidence}

In the period 2000-2017, on average, 579 children and young adolescents were diagnosed with cancer in the Netherlands annually, including the benign and borderline CNS tumours (Fig. 2A). The average ASR of childhood cancer was 168 per million person-years (Fig. 2B). The boys were slightly more affected than girls with an M:F ratio of 1.2 (ASR was 180 per million in boys versus 156 in girls). The average incidence rate also differed by age group. Children aged 5-9 years had the lowest incidence with 127 per million person-years, followed by teenagers aged 10-14 years with 135 per million. The highest incidence was observed in infants (0 years) with 230 per million person-years.

\subsection{Cancer incidence trends over time}

The average number of new cancer cases, ASR per million person-years and AAPC by diagnostic (sub) group in children and young adolescents (aged 0-17 years) are shown in Table 1. Benign and borderline CNS tumours were not taken into account in these trend analyses, but are separately presented in Table S2. Childhood cancer incidence increased significantly over time by $0.6 \%$ per year $(95 \%$ CI $0.3-0.8)$ from 144 per million person-years in 1990-1999 to 162 in 2010-2017, and was seen in both sexes, in infants (aged 0 years), teenagers (aged 10-14 years) and young adolescents (aged 15-17 years; Table 1 and Fig. 3A and B). Significant increases were observed for leukaemia $(+0.7 \%$ per year, 95\% CI $0.3-1.2)$, CNS tumours $(+1.0 \%$ per year, $0.5-1.5$ ), neuroblastoma (i.e. diagnostic subgroup IVa; $+1.2 \%$ per year, $0.1-2.2$ ) and Ewing bone tumours $(+2.4 \%$ per year, $0.9-4.0)$. Evaluation of trend transitions during the study period using joinpoint analysis are shown in Table 2.

Incidence increases of leukaemia were observed in girls (from 35 per million person-years in 1990-1999 to 44 in 2010-2017; a rise of 1.1\% annually, 95\% CI 0.4-1.8) and in infants (from 31 in 1990-1999 to 50 in 2010-2017; 
Table 1

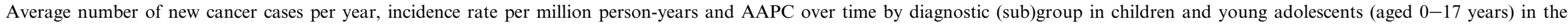
Netherlands, 1990-2017.

\begin{tabular}{|c|c|c|c|c|c|c|c|c|c|c|c|}
\hline & \multirow{2}{*}{$\begin{array}{l}\text { Total number } \\
\text { of cases } \\
1990-2017\end{array}$} & \multicolumn{4}{|c|}{ Average number of new cases per year } & \multicolumn{4}{|c|}{ Average incidence rate per million person-years ${ }^{\mathrm{c}}$} & \multirow[t]{2}{*}{$\begin{array}{l}\text { AAPC }^{\mathrm{d}} \\
(\%)\end{array}$} & \multirow[t]{2}{*}{$95 \%$ CI } \\
\hline & & $1990-2017$ & $1990-1999$ & $2000-2009$ & $2010-2017$ & $1990-2017$ & 1990-1999 & $2000-2009$ & $2010-2017$ & & \\
\hline All cancers & 14,527 & 519 & 481 & 538 & 542 & 152.7 & 144.2 & 154.1 & 161.5 & 0.6 & $0.3-0.8$ \\
\hline \multicolumn{12}{|l|}{ Gender } \\
\hline Boys & 8079 & 289 & 269 & 301 & 297 & 166.0 & 158.3 & 168.1 & 172.9 & 0.5 & $0.2-0.8$ \\
\hline Girls & 6448 & 230 & 211 & 237 & 245 & 138.8 & 129.5 & 139.4 & 149.7 & 0.7 & $0.3-1.1$ \\
\hline \multicolumn{12}{|l|}{ Age (in years) } \\
\hline 0 & 1099 & 39 & 36 & 40 & 42 & 208.8 & 184.8 & 207.4 & 240.5 & 1.5 & $0.4-2.5$ \\
\hline $1-4$ & 4188 & 150 & 147 & 154 & 147 & 195.3 & 189.4 & 194.1 & 204.2 & 0.4 & -0.1 to 0.8 \\
\hline $5-9$ & 3101 & 111 & 102 & 121 & 109 & 114.8 & 108.0 & 121.3 & 115.2 & 0.4 & -0.2 to 0.9 \\
\hline $10-14$ & 3228 & 115 & 102 & 120 & 126 & 119.2 & 111.3 & 121.2 & 126.5 & 0.6 & $0.3-1.0$ \\
\hline $15-17$ & 2911 & 104 & 94 & 103 & 118 & 178.4 & 168.0 & 175.3 & 195.2 & 0.7 & $0.2-1.2$ \\
\hline All cancers without pilocytic astrocytomas & 13,653 & 488 & 456 & 503 & 508 & 143.6 & 137.0 & 144.0 & 151.5 & 0.5 & $0.3-0.7$ \\
\hline \multicolumn{12}{|l|}{ ICCC-3 diagnostic group } \\
\hline I. Leukaemia’s & 4103 & 147 & 134 & 156 & 151 & 44.8 & 41.4 & 46.2 & 47.3 & 0.7 & $0.3-1.2$ \\
\hline Ia. Lymphoid leukaemia’s & 3189 & 114 & 105 & 122 & 115 & 35.0 & 32.6 & 36.3 & 36.3 & 0.6 & $0.1-1.1$ \\
\hline Ib. Acute myeloid leukaemia's & 728 & 26 & 24 & 26 & 28 & 7.8 & 7.3 & 7.7 & 8.5 & 0.8 & -0.1 to 1.7 \\
\hline Ic. Chronic myeloproliferative diseases & 83 & 3 & 2 & 4 & 4 & 0.8 & 0.6 & 0.9 & 1.0 & NA & \\
\hline Id \& Ie. Other \& unspecified leukaemias & 103 & 4 & 3 & 4 & 5 & 1.2 & 0.9 & 1.2 & 1.4 & NA & \\
\hline II. Lymphomas & 2098 & 75 & 72 & 75 & 79 & 20.2 & 20.1 & 19.8 & 20.8 & 0.2 & -0.3 to 0.8 \\
\hline IIa. Hodgkin lymphomas & 1013 & 36 & 33 & 38 & 38 & 9.4 & 8.9 & 9.7 & 9.7 & 0.6 & -0.3 to 1.4 \\
\hline IIb. Non-Hodgkin lymphomas & 711 & 25 & 25 & 23 & 29 & 7.0 & 7.2 & 6.3 & 7.7 & 0.3 & -0.7 to 1.4 \\
\hline IIc. Burkitt lymphomas & 359 & 13 & 14 & 13 & 11 & 3.7 & 4.0 & 3.7 & 3.2 & -0.8 & -2.3 to 0.7 \\
\hline IId \& IIe. Other \& unspecified lymphomas & 15 & 1 & 0 & 1 & 1 & 0.1 & 0.1 & 0.1 & 0.2 & NA & \\
\hline III. CNStumours ${ }^{\mathrm{a}}$ & 2819 & 101 & 88 & 104 & 112 & 29.7 & 26.5 & 29.8 & 33.6 & 1.0 & $0.5-1.5$ \\
\hline IIIa. Ependymomas and choroid plexus tumours & 272 & 10 & 10 & 10 & 8 & 3.0 & 3.2 & 3.1 & 2.6 & -1.0 & -2.4 to 0.5 \\
\hline IIIb/d. Astrocytomas \& gliomas & 1727 & 62 & 51 & 66 & 70 & 17.9 & 15.2 & 18.5 & 20.4 & 1.3 & $0.7-1.9$ \\
\hline Pilocytic astrocytomas (ICD-O-3 M9421) & 874 & 31 & 25 & 36 & 34 & 9.1 & 7.3 & 10.1 & 10.1 & 1.8 & $0.8-2.8$ \\
\hline Astrocytomas NOS (ICD-O-3 M9400 and 9430) & 212 & 8 & 13 & 4 & 5 & 2.2 & 3.7 & 1.2 & 1.5 & NA & \\
\hline Gliomas NOS (ICD-O-3 M9380) & 265 & 9 & 2 & 11 & 17 & 2.8 & 0.6 & 3.2 & 5.0 & NA & \\
\hline IIIc. Embryonal tumours & 616 & 22 & 19 & 24 & 24 & 6.7 & 5.8 & 6.9 & 7.5 & 1.2 & $0.1-2.3$ \\
\hline IIIe \& IIIf. Other \& unspecified CNS tumours & 204 & 8 & 8 & 5 & 10 & 2.2 & 2.3 & 1.3 & 3.1 & 1.3 & -1.5 to 4.1 \\
\hline III. CNS tumours without pilocytic astrocytomas & 1945 & 69 & 64 & 69 & 78 & 20.6 & 19.2 & 19.7 & 23.5 & 0.7 & $0.1-1.4$ \\
\hline IV. Neuroblastoma and other peripheral nervous cell tumours & 689 & 25 & 22 & 26 & 26 & 8.2 & 7.4 & 8.2 & 9.2 & 1.0 & $0.1-2.0$ \\
\hline IVa. Neuroblastoma & 667 & 24 & 21 & 25 & 26 & 8.0 & 7.1 & 8.1 & 9.0 & 1.2 & $0.1-2.2$ \\
\hline V. Retinoblastoma ${ }^{\mathrm{b}}$ & 341 & 12 & 13 & 11 & 13 & 6.9 & 7.2 & 6.1 & 7.5 & -0.6 & -2.6 to 1.4 \\
\hline VI. Renal tumours & 723 & 26 & 26 & 27 & 24 & 8.5 & 8.4 & 8.7 & 8.3 & -0.2 & -1.4 to 1.0 \\
\hline VII. Hepatic tumours & 175 & 6 & 6 & 7 & 5 & 2.0 & 1.9 & 2.3 & 1.7 & 1.3 & -1.2 to 3.8 \\
\hline VIII. Bone tumours & 895 & 32 & 28 & 35 & 34 & 8.5 & 7.7 & 9.0 & 8.9 & 0.8 & -0.2 to 1.8 \\
\hline VIIIa. Osteosarcomas & 437 & 16 & 15 & 17 & 15 & 4.1 & 4.0 & 4.3 & 3.8 & -0.5 & -2.2 to 1.1 \\
\hline VIIIb. Chondrosarcomas & 21 & 1 & 1 & 1 & 1 & 0.2 & 0.2 & 0.2 & 0.2 & NA & \\
\hline VIIIc. Ewing tumours & 340 & 12 & 10 & 13 & 14 & 3.3 & 2.8 & 3.4 & 3.8 & 2.4 & $0.9-4.0$ \\
\hline VIIId \& VIIIe. Other \& unspecified bone tumours & 97 & 3 & 2 & 4 & 4 & 0.9 & 0.7 & 1.1 & 1.0 & NA & \\
\hline IX. Soft tissue sarcomas & 977 & 35 & 35 & 34 & 35 & 10.1 & 10.5 & 9.8 & 10.0 & $\begin{array}{l}-0.6 \\
\text { ontinued }\end{array}$ & $\begin{array}{l}-1.5 \text { to } 0.3 \\
\text { on next page) }\end{array}$ \\
\hline
\end{tabular}




\begin{tabular}{|c|c|c|c|c|c|c|c|c|c|c|c|}
\hline & \multirow{2}{*}{$\begin{array}{l}\text { Total numbe } \\
\text { of cases }\end{array}$} & \multicolumn{4}{|c|}{ Average number of new cases per year } & \multicolumn{4}{|c|}{ Average incidence rate per million person-years ${ }^{\mathrm{c}}$} & \multirow[t]{2}{*}{$\begin{array}{l}\text { AAPC }^{\mathrm{d}} \\
(\%)\end{array}$} & \multirow[t]{2}{*}{$95 \%$ CI } \\
\hline & & $1990-2017$ & 1990-1999 & $2000-2009$ & 2010-2017 & $1990-2017$ & 1990-1999 & $2000-2009$ & $2010-2017$ & & \\
\hline IXa. Rhabdomyosarcomas & 514 & 18 & 20 & 17 & 17 & 5.5 & 6.2 & 5.0 & 5.2 & -1.2 & -2.4 to -0.1 \\
\hline IXb \& IXe. Other \& unspecified soft tissue sarcomas & 463 & 17 & 15 & 17 & 18 & 4.6 & 4.3 & 4.8 & 4.8 & 0.2 & -1.0 to 1.4 \\
\hline X. Germ cell \& gonadal tumours & 727 & 26 & 27 & 24 & 27 & 7.3 & 7.9 & 6.5 & 7.6 & -0.1 & -1.0 to 0.8 \\
\hline Xa. Intracranial and intraspinal germ cell tumours & 126 & 5 & 5 & 4 & 4 & 1.2 & 1.4 & 1.1 & 1.1 & -1.0 & -3.9 to 1.8 \\
\hline $\mathrm{Xb}$. Extracranial and extragonadal germ cell tumours & 138 & 5 & 5 & 4 & 6 & 1.7 & 1.7 & 1.4 & 2.0 & 1.4 & -0.7 to 3.5 \\
\hline Xc. Gonadal germ cell tumours: testis & 269 & 10 & 10 & 8 & 11 & 5.1 & 5.7 & 4.2 & 5.5 & -0.8 & -2.5 to 0.9 \\
\hline Xc. Gonadal germ cell tumours: ovary & 154 & 6 & 5 & 6 & 6 & 3.0 & 3.0 & 3.0 & 2.8 & 0.4 & -1.9 to 2.7 \\
\hline Xd \& Xe. Other \& unspecified gonadal tumours & 40 & 1 & 2 & 2 & 1 & 0.4 & 0.4 & 0.4 & 0.2 & NA & \\
\hline XI. Other epithelial tumours & 942 & 34 & 29 & 38 & 35 & 8.9 & 8.0 & 9.7 & 9.0 & 0.9 & -0.1 to 1.9 \\
\hline XIb. Thyroid carcinomas & 255 & 9 & 9 & 8 & 11 & 2.4 & 2.4 & 2.2 & 2.8 & 1.7 & -0.5 to 4.0 \\
\hline XId. Malignant melanoma & 414 & 15 & 12 & 18 & 14 & 3.9 & 3.3 & 4.8 & 3.6 & 1.1 & -0.2 to 2.5 \\
\hline XIa, XIc, XIe \& XIf. Other \& unspecified epithelial tumours & 273 & 10 & 9 & 11 & 10 & 2.6 & 2.3 & 2.8 & 2.6 & 0.3 & -1.5 to 2.1 \\
\hline XII. Other and unspecified tumours & 37 & 1 & 1 & 1 & 2 & 0.4 & 0.3 & 0.4 & 0.6 & NA & \\
\hline
\end{tabular}

NA, estimation of a reliable average annual percentage change was not possible because of $\mathrm{N}=0$ in $\geq 1$ incidence year.

AAPC, average annual percentage change; CI, confidence interval; CNS, central nervous system; ICCC, International Classification of Childhood Cancer

${ }^{a}$ Including pilocytic astrocytomas, other CNS tumours having a behaviour code/ 0 and/1 and completely registered since 2000 only were excluded and those tumours are separately described in Table S2.

b Numbers, rates and average annual percentage change calculated for 0-9 years old, only.

${ }^{\mathrm{c}}$ Incidence rates were standardised following the World Standard Population [12]; age-specific incidence rates were calculated for age groups consisting $\leq 5$ years.

d AAPC values in bold correspond to significant changes in the incidence trend. 

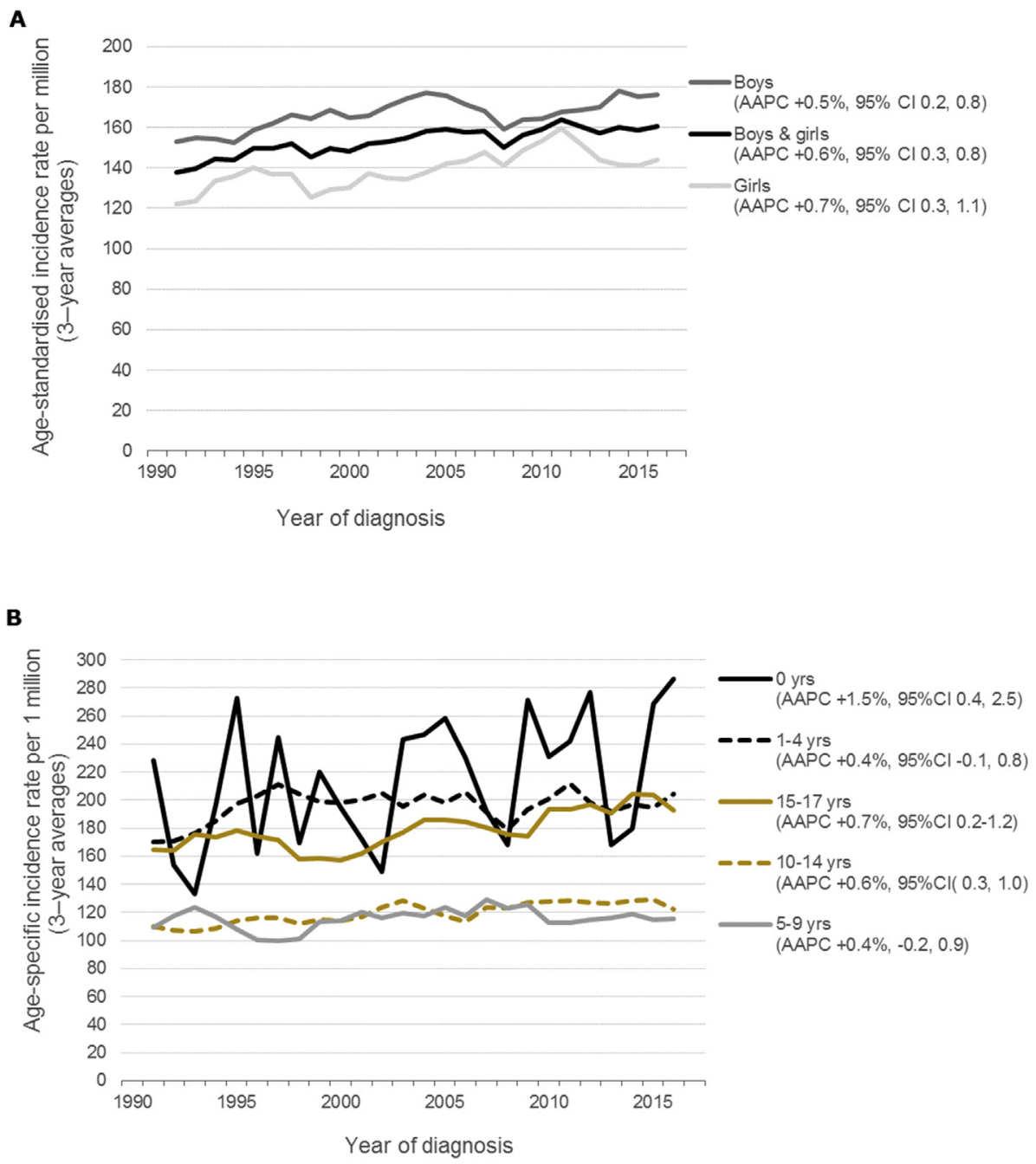

Fig. 3. Trends in incidence of childhood and adolescent cancer by gender and age in the Netherlands, 1990-2017 (Source: The Netherlands Cancer Registry). A) Age-standardised incidence rates [12] by gender over time. B) Age-specific incidence rates by age group over time. AAPC estimated from a regression line, which was fitted to the natural logarithm of the rates using calendar year as regressor variable. Note: Benign and borderline CNS tumours were excluded. AAPC, Average Annual Percentage Change; CI, confidence interval.

$+3.1 \%$ per year, 1.2-5.1), with no trend transitions. Except for the boys, a temporary incidence increase was seen during the time segment $1990-1997$ by $4.8 \%$ per year (95\% CI 0.4-9.4) followed by a stable incidence at 52 per million. In young adolescents, incidence tended to increase by $1.4 \%$ per annum ( $95 \% \mathrm{CI}-0.0$ to 2.9$)$, from 23 per million person-years in 1990-1999 to 29 in 2010-2017. Lymphoid leukaemia (LL) represented 77\% of all leukaemias and mainly responsible for the significant increase of leukaemia (LL $+0.6 \%$ per year, $95 \% \mathrm{CI}$ 0.1-1.1; Table 1). Incidence of three main types of lymphomas remained stable over time (Table 1).

Incidence increases of CNS tumours were seen in both sexes with a rise of $1.0 \%$ per year (boys: from 28 per million person-years in 1990-1999 to 36 in 2010-2017; girls: from 25 in 1990-1999 to 32 in 2010-2017) and in young children below the age of 5 years with a rise of $1.3 \%$ annually ( $95 \%$ CI $0.5-2.0$; from 31 per million in 1990-1999 to 42 in 2010-2017), with no significant changes in trend (Table 2). The increase of CNS tumours was caused by increases of astrocytomas/gliomas and embryonal CNS tumours $(+1.3 \%$ annually, $95 \%$ CI $0.7-1.9$ and $+1.2 \%$ per year, $0.1-2.3$, respectively) comprising $83 \%$ of all CNS tumours. Pilocytic astrocytomas represented half of the astrocytomas/gliomas and partially responsible for the significant increase in incidence of astrocytomas/gliomas $(+1.8 \%$ per year, $95 \%$ CI $0.8-2.8$; Table 1$)$. In joinpoint analysis, the trend of pilocytic astrocytomas increased until 2010 by $3.4 \%$ per annum $(95 \%$ CI $2.0-4.8)$ followed by a stable incidence at 10 per million personyears. The same pattern was visible in girls and 5-9 years old ones (Table 2). Simultaneously, a decline in unspecified astrocytomas was observed from 3.7 per million person-years in 1990-1999 to 1.5 in 2010-2017. By contrast, unspecified gliomas increased from 0.7 per million person-years in 1990-1999 to 5.0 in recent years. Most of these cases were coded at the brain stem (ICD- 
O-3 site C71.7; 79\%) and were not microscopically verified $(82 \%)$. In the 1990 s, unspecified gliomas of the brain stem were also registered with morphology code M8000, which declined over time from 0.6 per million person-years in 1990-1999 to 0.1 in 2010-2017.

The incidence of neuroblastoma (i.e. diagnostic subgroup IVa) has risen significantly from 7.1 per million person-years in 1990-1999 to 9.0 in 2010-2017 with no joinpoints. The increase of Ewing bone tumours was observed in boys with a rise of $3 \%$ annually $(95 \%$ CI 1.0-5.1), from 3.0 per million person-years in 1990-1999 to 4.1 in $2010-2017$ with no trend transitions (Table 2). The same pattern was seen in all tumours of the Ewing sarcoma family (diagnostic subgroups VIIIc and IXd.1-d.2), incidence increased by $2.3 \%(95 \%$ CI $0.8-3.7)$ from 3.4 per million personyears in 1990-1999 to 4.8 in 2010-2017, mainly seen in boys in which the incidence rate rose to 5.3 in 2010-2017 (+3\% annually, 95\% CI 0.9-5.1).

From the epithelial tumours, thyroid cancer seemed to increase in young adolescents from 5.9 per million person-years in 1990-1999 to 10 in 2010-2017 $(+3 \%$ per annum, $95 \% \mathrm{CI}-0.2$ to 6.2$)$. A temporary increase in the incidence of malignant melanomas was observed during $1990-2002$ by $+6.5 \%$ per year $(95 \%$ CI $2.7-11)$, and tended to decrease afterwards by $-2.5 \%$ per year ( -5.0 to 1.0 ; Table 2$)$.

\subsection{Changes in stage at diagnosis over time}

Time trends in stage at diagnosis by diagnostic (sub) group in children and young adolescents are presented in Fig. 4. Shifts in stage were observed for Hodgkin lymphoma, non-rhabdomyosarcomas, testicular germ
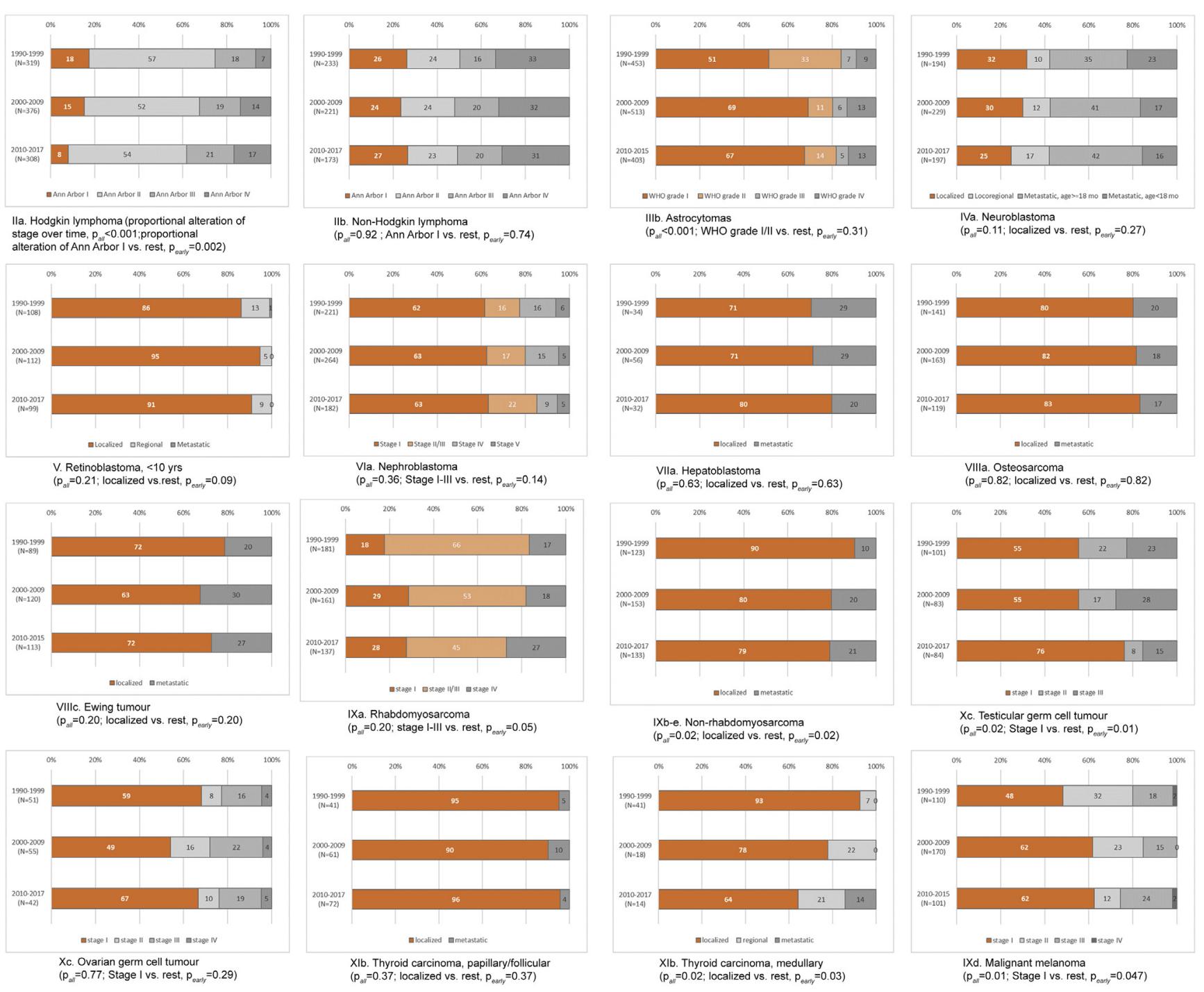

Fig. 4. Time trends in stage at diagnosis by diagnostic ICCC-3 (sub)groups and period of diagnosis in children and young adolescents (aged 0-17 years) in the Netherlands, 1990-2017 (Source: The Netherlands Cancer Registry). Staging criteria of each ICCC-3 diagnostic (sub)group are described in Table S1. Early-stage disease is highlighted in orange shades. Note: Benign and borderline astrocytomas were excluded. WHO, World Health Organisation. 
Table 2

Trends in incidence of cancer in children and young adolescents (aged 0-17 years) for the entire study period and for any time segment identified in joinpoint analysis by diagnostic ICCC-3 (sub)group, gender and age at diagnosis in the Netherlands, 1990-2017 a,b.

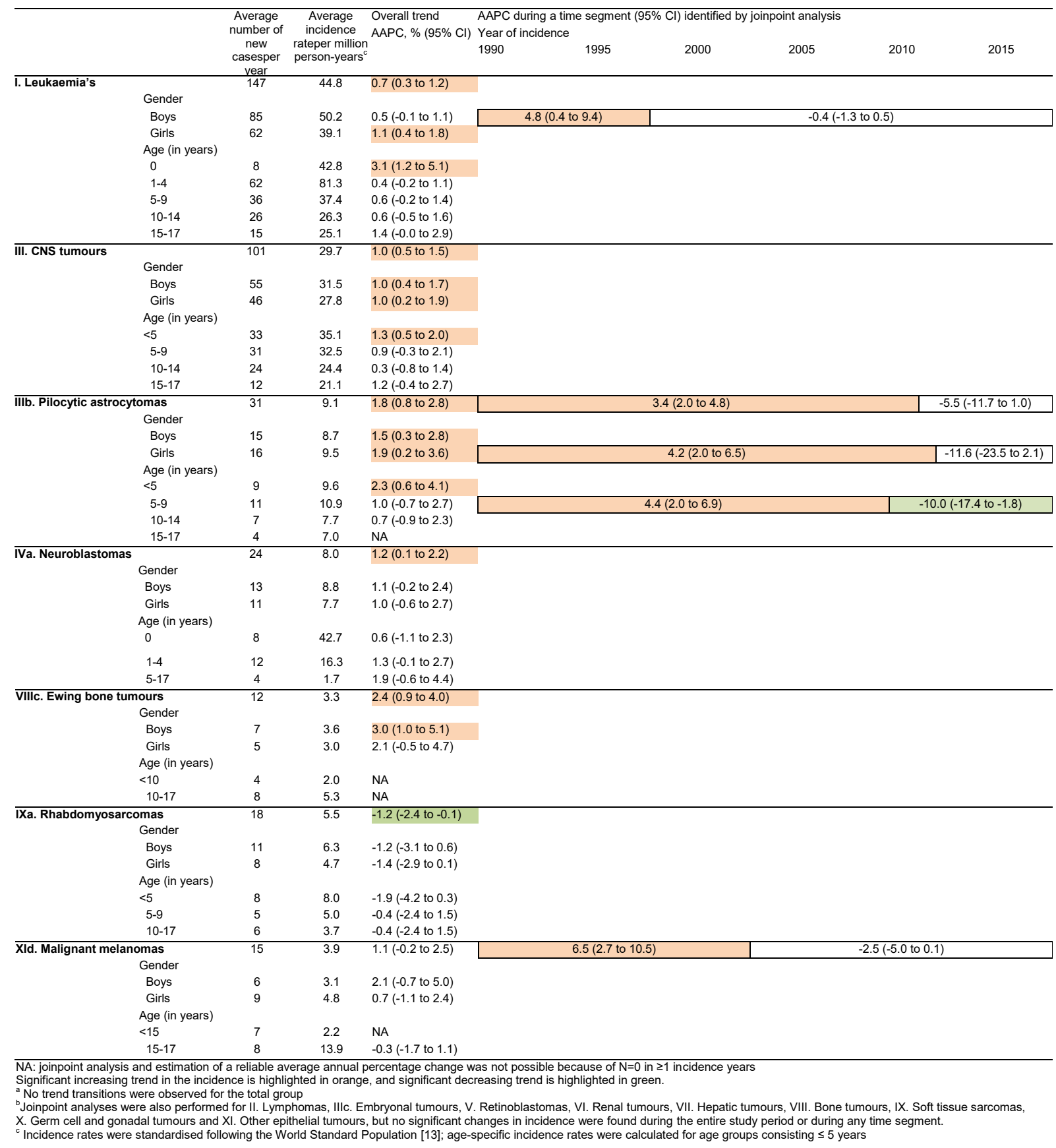

cell tumours, medullary thyroid carcinomas and malignant melanomas. For testicular germ cell tumours and malignant melanomas, early-stage disease increased over time: stage I testicular germ cell tumours rose from $55 \%$ in $1990-2009$ to $76 \%$ in $2010-2017(p=0.01)$, and stage I melanomas showed a rise from $48 \%$ in $1990-1999$ to $62 \%$ in $2000-2017$ ( $p=0.047$ ). The degree of malignancy in astrocytomas shifted towards WHO grade I and increased from 51\% in 1990-1999 to $67 \%$ in $2010-2017(p<0.001)$.
A shift to more advanced disease at diagnosis was seen in Hodgkin lymphomas, rhabdomyosarcomas, non-rhabdomyosarcomas and medullary thyroid carcinomas. Hodgkin's Ann Arbor I declined from 18\% in 1990-1999 to 8\% in 2010-2017 ( $p=0.002)$ mainly due to an increase in Ann Arbor IV. Early-stage disease of rhabdomyosarcomas slightly decreased from $83 \%$ in $1990-1999$ to $73 \%$ in $2010-2017$ ( $p=0.05$ ) mainly due to a decrease in stage II/III and a rise in stage IV. The same pattern was observed in non-rhabdomyosarcomas 
(from $90 \%$ to $79 \%, p=0.02$ ) due to an increase in metastatic disease. Localised medullary thyroid carcinoma declined from $93 \%$ in $1990-1999$ to $64 \%$ in 2010-2017 $(p=0.01)$, whereas regional and metastatic disease increased (Fig. 4).

\section{Discussion}

This is the first nationwide, population-based study on time trends in incidence of childhood and young adolescent cancer in the Netherlands. Over a 28-year period, the overall cancer incidence increased by an average of $+0.6 \%$ annually. This increase in incidence was especially seen in infants, teenagers and young adolescents, and in the diagnostic (sub)groups: leukaemia, malignant CNS tumours, neuroblastoma and Ewing sarcoma. Rise in early-stage disease was seen in testicular germ cell tumours and malignant melanomas only, whereas a stage migration to more advanced stages was observed for Hodgkin lymphomas, soft tissue sarcomas and medullary thyroid carcinomas.

The slight increase in the overall cancer incidence since the 1990s is in line with a recent international pooling of European data, which showed an average increase of $+0.5 \%$ per year in children younger than 15 years, and $+1.0 \%$ in adolescents (aged 15-19 years) during 1991-2010 [1]. A steady rise in cancer incidence among children has been seen in the developed countries since the 1950s [2,16]. Reasons for this rise are difficult to pin down as changes in diagnostic procedures and imaging, but also in registry procedures have taken place, and the aetiology of cancer in children is still largely unknown $[2,17]$.

Advances in diagnostic technology may result in an increased (earlier) detection and/or stage migration. In this study, increased detection was observed for lowgrade pilocytic astrocytomas until 2010, especially in young children $(<10$ years), which partly caused the total increase of CNS tumours. This finding is a result of a shift from unspecified astrocytomas towards pilocytic astrocytomas and most likely due to an increasing use of magnetic resonance imaging (MRI). This is consistent with a study from Great Britain in the 1990s [17], although the incidence increase started later in the Netherlands. Probably, the rise in unspecified gliomas at the brain stem is partially also due to the increased use of MRI. Simultaneously, a rise in high-grade embryonal CNS tumours was observed. This might be a result of increasing use of molecular diagnostic tools combined with a higher diagnostic awareness of atypical teratoid/ rhabdoid tumours because its recognition as a distinct pathologic entity since the mid-1990s [18]. However, in other countries, a simultaneous decreasing trend for unspecified embryonal CNS tumours was detected and even a decreasing trend for medulloblastomas [19-21]. In this study, detailed trend analyses of the subtypes were not performed and therefore the exact cause of the observed rise in embryonal CNS tumours remains unclear.

Stage migration towards advanced-stage disease as a result of improved and more precise diagnostics was seen in Hodgkin lymphomas, soft tissue sarcomas and medullary thyroid carcinomas (MTC). However, these changes did not result into an increasing incidence [23] For MTCs even a lower incidence was observed which might be the result of prophylactic surgery for multiple endocrine neoplasia 2a and 2b. Since 1993, genetic screening has been introduced in the Netherlands to identify carriers of these syndromes to prevent MTC by early prophylactic thyroid surgery which resulted in more frequent findings of thyroids with $\mathrm{C}$-cell hyperplasia instead of MTC $[37,38]$. This might also explain the stage shift in MTCs. The opposite, an increased proportion of early-stage disease, was observed in malignant melanomas and testicular germ cell tumours. For melanomas, this is due to the increased diagnostic awareness among general practitioners, dermatologists and the general population as a result of prevention campaigns [24]. Causes for the rise in early disease of testicular germ cell tumours is less clear and probably a mix of increased diagnostic awareness among general practitioners and the use of more sensitive imaging modalities [25].

The effect of improved diagnostics and diagnostic awareness on the rising incidences of leukaemia, neuroblastoma and Ewing tumours is less clear. The largest increase of leukaemia was made during the 1990s and most visible in infants. Under-diagnosis in the past could be a reason as shown in a study from the United Kingdom, where acute lymphoblastic leukaemia was under-diagnosed in poorer communities [26]. However, this seems not valid for our finding as the Netherlands has a high-quality system of child health care. Over $90 \%$ of all children up to the age of 4 years visit the free public service of child health clinics that monitor health and social development on a regular basis [27]. A recent publication of our group showed that the rising incidence of neuroblastoma could not be explained by registration artefacts, immigration of paediatric patients to the Netherlands or improved diagnostics [28]. For the observed increase in Ewing tumours, we do not expect that diagnostics play a role. Despite of the difficulty in interpretation of biopsy specimens, a pathology review in the Netherlands showed that agreement on original diagnosis was almost perfect for Ewing tumours [29].

The possibility of real changes in background risk factors cannot be excluded as a cause of the observed increasing childhood cancer incidence. Etiological factors are largely unknown for most childhood cancers, but changes in social structures (e.g. older maternal age, increasing percentage of Caesarean deliveries, birth weight, family size, attitudes regarding breastfeeding and immunisation, daycare attendance), socioeconomic 
situation, exposure to artificial and natural substances (e.g. ionising radiation, electromagnetic fields, pesticides, etc.) during the last decades might have some impact on the development of childhood cancer [1,2,30-33]. Most of those risk factors have been associated with leukaemia [34].

The strength of our study was its population-based nature and the NCR not having age or hospital limits (i.e. inclusion of children and young adolescents who might not have been treated by a paediatric oncologist). In a previous study, we have linked the NCR with the Registry of the Dutch Childhood Oncology Group, which showed that $18 \%$ of children and adolescents with cancer below the age of 18 years were not known in paediatric oncology centres [6]. A limitation of this study is the missing stage information of ependymomas and embryonal CNS tumours as the Toronto staging guidelines were implemented in the NCR since 2018. Furthermore, there were changes in stage registration over time: during 1990-2002, TNM classification was used for blastomas, whereas since 2003, the extent of disease was used. However, it was possible to generate stage categories based on both staging classifications (Table S1), and the distribution of stages was in line with a population-based study from Australia, which described the distribution of cases by stage at diagnosis for the first time [35]. Moreover, we have tried to minimise the influence of registration artefacts by excluding those tumours that were not registered completely during our study period.

\section{Conclusion}

In conclusion, this is the first study that describes the incidence for children and young adolescents in the Netherlands including the unique information on stage at diagnosis. Rise in early-stage disease was found for a few childhood cancers only, but could not explain the total increase in cancer incidence. Improved diagnostics and increased diagnostic awareness have mainly led to higher proportions of advanced disease. Real changes in background factors seem of more importance in explaining the incidence increase.

\section{Funding}

The present work is funded by the Stichting Kinderen Kankervrij (KiKa; project number 207.

\section{Role of the funding source}

The funding sources had no role in study design, collection, analysis and interpretation of data, or writing of this manuscript, or the decision to submit the article for publication.

\section{Conflict of interest statement}

None declared.

\section{Acknowledgements}

The authors would like to thank the KiKa for funding this study, and the registration team of the Netherlands Comprehensive Cancer Organization (IKNL) for the collection of data for the Netherlands Cancer Registry. The authors also thank Hanneke van Santen for useful discussion and suggestions.

\section{Appendix A. Supplementary data}

Supplementary data to this article can be found online at https://doi.org/10.1016/j.ejca.2020.04.011.

\section{References}

[1] Steliarova-Foucher E, Fidler MM, Colombet M, Lacour B, Kaatsch P, Pineros M, et al. Changing geographical patterns and trends in cancer incidence in children and adolescents in Europe, 1991-2010 (Automated Childhood Cancer Information System): a population-based study. Lancet Oncol 2018;19:1159-69.

[2] Kaatsch P. Epidemiology of childhood cancer. Cancer Treat Rev 2010;36:277-85.

[3] Gatta G, Botta L, Rossi S, Aareleid T, Bielska-Lasota M, Clavel J, et al. Childhood cancer survival in Europe 1999-2007: results of EUROCARE-5-a population-based study. Lancet Oncol 2014;15:35-47.

[4] Steliarova-Foucher E, Colombet M, Ries LAG, Moreno F, Dolya A, Bray F, et al. International incidence of childhood cancer, 2001-10: a population-based registry study. Lancet Oncol 2017;18:719-31.

[5] Autier P. Increasing incidence of cancer in children and competing risks. Lancet Oncol 2018;19:1136-7.

[6] Reedijk AMJ, van der Heiden-van der Loo M, Visser O, KarimKos HE, Lieverst JA, de Ridder-Sluiter JG, et al. Site of childhood cancer care in The Netherlands. Eur J Cancer 2017;87: $38-46$.

[7] Reedijk AM, Janssen-Heijnen ML, Louwman MW, Snepvangers Y, Hofhuis WJ, Coebergh JW. Increasing incidence and improved survival of cancer in children and young adults in Southern Netherlands, 1973-1999. Eur J Cancer 2005;41:760-9.

[8] Steliarova-Foucher E, Stiller C, Lacour B, Kaatsch P. International classification of childhood cancer, 3rd ed. Cancer 2005;103: 1457-67.

[9] Carbone PP, Kaplan HS, Musshoff K, Smithers DW, Tubiana M. Report of the committee on Hodgkin's disease staging classification. Cancer Res 1971:31:1860-1.

[10] Sobin LH, Gospodarowicz MK, Wittekind C, Cancer IUa. TNM classification of malignant tumours. 7th ed. Chichester, West Sussex, UK ; Hoboken, NJ: Wiley-Blackwell; 2009. 2010.

[11] Aitken JF, Youlden DR, Moore AS, Baade PD, Ward LJ, Thursfield VJ, et al. Assessing the feasibility and validity of the Toronto childhood cancer stage guidelines: a populationbased registry study. Lancet Child Adolesc Health 2018;2: $173-9$.

[12] Segi M, Fujisaku S, Kurihara M, Narai Y, Sasajima K. The ageadjusted death rates for malignant neoplasms in some selected sites in 23 countries in 1954-1955 and their geographical correlation. Tohoku J Exp Med 1960;72:91-103. 
[13] Boyle P, Parkin DM. Cancer registration: principles and methods. Statistical methods for registries. IARC Sci Publ 1991:126-58.

[14] Clegg LX, Hankey BF, Tiwari R, Feuer EJ, Edwards BK. Estimating average annual per cent change in trend analysis. Stat Med 2009;28:3670-82.

[15] Kim HJ, Fay MP, Feuer EJ, Midthune DN. Permutation tests for joinpoint regression with applications to cancer rates. Stat Med 2000;19:335-51.

[16] Steliarova-Foucher E, Stiller C, Kaatsch P, Berrino F, Coebergh JW, Lacour B, et al. Geographical patterns and time trends of cancer incidence and survival among children and adolescents in Europe since the 1970s (the ACCIS project): an epidemiological study. Lancet 2004;364:2097-105.

[17] Kroll ME, Carpenter LM, Murphy MF, Stiller CA. Effects of changes in diagnosis and registration on time trends in recorded childhood cancer incidence in Great Britain. Br J Cancer 2012; 107:1159-62.

[18] Rorke LB, Packer RJ, Biegel JA. Central nervous system atypical teratoid/rhabdoid tumors of infancy and childhood: definition of an entity. J Neurosurg 1996;85:56-65.

[19] Fairley L, Picton SV, McNally RJ, Bailey S, McCabe MG, Feltbower RG. Incidence and survival of children and young people with central nervous system embryonal tumours in the North of England, 1990-2013. Eur J Cancer 2016;61: $36-43$

[20] Tulla M, Berthold F, Graf N, Rutkowski S, von Schweinitz D, Spix C, et al. Incidence, trends, and survival of children with embryonal tumors. Pediatrics 2015;136:e623-32.

[21] Johnston DL, Keene D, Kostova M, Strother D, Lafay-Cousin L, Fryer C, et al. Incidence of medulloblastoma in Canadian children. J Neuro Oncol 2014;120:575-9.

[23] Reedijk AMJ, Zijtregtop EAM, Coebergh JWW, MeyerWentrup FAG, Hebeda KM, Zwaan CM, et al. Improved survival for adolescents and young adults with Hodgkin lymphoma and continued high survival for children in The Netherlands: a population-based study during 1990-2015. Br J Hematol 2020. https://doi.org/10.1111/bjh.16491.

[24] Eggen CAM, Durgaram VVL, van Doorn R, Mooi WJ, Pardo LM, Pasmans S, et al. Incidence and relative survival of melanoma in children and adolescents in The Netherlands, 19892013. J Eur Acad Dermatol Venereol 2018;32:956-61.

[25] Verhoeven RH, Karim-Kos HE, Coebergh JW, Brink M, Horenblas S, de Wit R, et al. Markedly increased incidence and improved survival of testicular cancer in The Netherlands. Acta Oncol 2014;53:342-50.

[26] Kroll ME, Stiller CA, Richards S, Mitchell C, Carpenter LM. Evidence for under-diagnosis of childhood acute lymphoblastic leukaemia in poorer communities within Great Britain. Br J Cancer 2012;106:1556-9.

[27] Siderius EJ, Carmiggelt B, Rijn CS, Heerkens YF. Preventive child health care within the framework of the Dutch health care system. J Pediatr 2016;177S:S138-41.

[28] Tas ML, Reedijk AMJ, Coebergh JWW, Kremer LC, KarimKos HE, Pieters R, et al. Neuroblastoma between 1990-2014 in The Netherlands: increased incidence and improved survival of high risk neuroblastoma. Eur J Cancer 2019;124:47-55.

[29] van den Berg H, Slaar A, Kroon HM, Taminiau AH, Hogendoorn P. Results of diagnostic review in pediatric bone tumors and tumorlike lesions. J Pediatr Orthop 2008;28:561-4.

[30] Spector LG, Pankratz N, Marcotte EL. Genetic and nongenetic risk factors for childhood cancer. Pediatr Clin N Am 2015;62:11-25.

[31] Garcia-Perez J, Morales-Piga A, Gomez-Barroso D, TamayoUria I, Pardo Romaguera E, Lopez-Abente G, et al. Risk of bone tumors in children and residential proximity to industrial and urban areas: new findings from a case-control study. Sci Total Environ 2017;579:1333-42.

[32] Marcotte EL, Thomopoulos TP, Infante-Rivard C, Clavel J, Petridou ET, Schuz J, et al. Caesarean delivery and risk of childhood leukaemia: a pooled analysis from the Childhood Leukemia International Consortium (CLIC). Lancet Haematol 2016:3:e176-85.

[33] Paltiel O, Tikellis G, Linet M, Golding J, Lemeshow S, Phillips G, et al. Birthweight and childhood cancer: preliminary findings from the International Childhood Cancer Cohort Consortium (I4C). Paediatr Perinat Epidemiol 2015;29:335-45.

[34] Health Council of the Netherlands. Childhood leukaemia and environmental factors. The Hague: Health Council of the Netherlands, publication; 2012, ISBN 978-90-5549-926-7. 2012/33.

[35] Youlden DR, Frazier AL, Gupta S, Pritchard-Jones K, Kirby ML, Baade PD, et al. Stage at diagnosis for childhood solid cancers in Australia: a population-based study. Cancer Epidemiol 2019;59:208-14.

[36] Louis DN, Ohgaki H, Wiestler OD, Cavenee WK, Burger PC, Jouvet A, et al. The 2007 WHO classification of tumours of the central nervous system. Acta Neuropathol 2007;114:97-109.

[37] Brandi ML, Gagel RF, Angeli A, Bilezikian JP, Beck-Peccoz P, Bordi C, et al. Guidelines for diagnosis and therapy of MEN type 1 and type 2. J Clin Endocrinol Metab 2001;86(12):5658-71.

[38] Wells Jr SA, Asa SL, Dralle H, Elisei R, Evans DB, Gagel RF, et al., American Thyroid Association Guidelines Task Force on Medullary Thyroid Carcinoma. Revised American Thyroid Association guidelines for the management of medullary thyroid carcinoma. Thyroid 2015;25(6):567-610. 